\title{
Radical Scavenging and Endogenous Defence System Inducing Activities of 5-[(4-Chlorophenoxy)methyl]- 1,3,4-oxadiazole-2-thiol: A Novel Antioxidant
}

\author{
N. SHEHZADI ${ }^{1 *}$, K. HUSSAIN, M. T. KHAN¹, N. I. BUKHARI, M. ISLAM, M. SALMAN, S. Z. SIDDIQUI², A. REHMAN² AND \\ M. A. ABBASI ${ }^{2}$ \\ Punjab University College of Pharmacy, University of the Punjab, Allama Iqbal Campus, Lahore-54000, ${ }^{1}$ The University \\ of Lahore, 1-Km, Defence Road (Off Raiwind Road), Bhobatian Chowk, ${ }^{2}$ Department of Chemistry, Government College \\ University, Lahore-54000, Pakistan
}

Shehzadi, et al.: Broad Spectrum Radical Scavenging effect of 5-[(4-Chlorophenoxy)methyl]-1,3,4oxadiazole-2-thiol

5-[(4-chlorophenoxy)methyl]-1,3,4-oxadiazole-2-thiol owing to the presence of-SH group is expected to have a significant reducing potential, which could be translated into antioxidant potential and to prove this, the present study explored the antioxidant potential and binding pattern of this compound to oxidative stressrelated protein targets. The antioxidant properties were determined using in vitro methods with ascorbic acid and butylated hydroxytoluene as standards while interactions of 5-[(4-chlorophenoxy)methyl]-1,3,4oxadiazole-2-thiol with protein tyrosine kinase $2-\beta$ and glutathione reductase were determined using online software, Mcule 1-Click Docking, 3DLigandSite and COACH. The antioxidant activity of 5-[(4-chlorophenoxy) methyl]-1,3,4-oxadiazole-2-thiol was found to be $89.30 \pm 0.013,81.20 \pm 0.002,80.52 \pm 0.016,54.81 \pm 0.007$, $52.87 \pm 0.008,34.44 \pm 0.019$ and $19.91 \pm 0.014 \%$ in hydrogen peroxide scavenging assay, 2,2-diphenyl-1picrylhydrazyl radical scavenging assay, phosphomolybdenum assay, nitric oxide scavenging assay, reducing power assay, ferric thiocyanate assay and $\beta$-carotene bleaching assay, respectively. In all these assays, EC $\mathrm{C}_{50}$ of 5-[(4-chlorophenoxy)methyl]-1,3,4-oxadiazole-2-thiol ranged from $0.32-0.93 \mathrm{mg} / \mathrm{ml}$. The docking results indicated excellent binding to protein tyrosine kinase 2- $\beta$ and glutathione reductase, maximum for the latter. The results of the present study revealed that 5-[(4-chlorophenoxy)methyl]-1,3,4-oxadiazole-2-thiol has the propensity to abrogate oxidation by inducing endogenous defence system and preventing radical chain reactions, hence might be considered a potential antioxidant for further investigations.

Key words: Antioxidant, molecular docking, glutathione reductase, protein tyrosine kinase 2- $\beta$, 5-[(4-chlorophenoxy)methyl]-1,3,4-oxadiazole-2-thiol

Free radicals (FRs), species having unpaired electron in their outermost orbit play a pivotal role in the origin of life, physiological adaptation and biological evolution $^{[1]}$. Many cellular biochemical processes, signal transduction, gene transcription and regulation of soluble guanylate are governed by FRs. Nitric oxide free radical (NO) is a very important signalling species that regulates relaxation and proliferation of vascular smooth muscles, leukocytes adhesion, platelets aggregation, angiogenesis, thrombosis, vascular tone and haemodynamics ${ }^{[2]}$.

Mammalian cells being constantly fortified with oxygen produce oxygen free radicals (OFR), hydroxyl $\left(\mathrm{OH}^{-}\right)$and superoxide $\left(\mathrm{O}_{2}^{-}\right)$, and reactive oxygen species (ROS), $\mathrm{NO}$, hypochlorous acid, hydrogen peroxide $\left(\mathrm{H}_{2} \mathrm{O}_{2}\right)$ and

*Address for correspondence

E-mail: naureentanveerkhan@gmail.com

November-December 2018 peroxynitrite as a by-product of aerobic metabolism ${ }^{[3,4]}$. Since, the rate of production and removal of FRs is balanced by reactions involving enzymes such as catalase, glutathione peroxidase, glutathione reductase and superoxide dismutase, and non-enzymatic processes such as thioredoxin, thiols and disulphidebonding, these species do not necessarily present any threat to the body under normal physiological conditions $^{[5]}$. Nevertheless, an imbalanced defence or

This is an open access article distributed under the terms of the Creative Commons Attribution-NonCommercial-ShareAlike 3.0 License, which allows others to remix, tweak, and build upon the work non-commercially, as long as the author is credited and the new creations are licensed under the identical terms

Accepted 15 October 2018

Revised 08 April 2018

Received 27 May 2017

Indian J Pharm Sci 2018;80(6):1125-1135 
overproduction, under-elimination and assimilation of FRs from the exogenous sources (electromagnetic radiation, pollution and smoking) can cause serious penalty to the biomolecules leading to inflammation, tissue injury and ultimately cell death. Long term oxidative damage is known to be the culprit cause of aging, cancer, neural and cardiovascular disorders, and liver diseases ${ }^{[6-12]}$. Protection against injury due to the FRs is possible only by ample intake of antioxidants, which delay or inhibit the oxidation of biomolecules by their reducing activity, free radical scavenging, complexation of pro-oxidant metals, and quenching of singlet oxygen. Such compounds not only prevent or postpone the onset of degenerative diseases but also improve the quality of life and save the cost of healthcare delivery.

5-[(4-Chlorophenoxy)methyl]-1,3,4-oxadiazole-2thiol (OXCPM, fig. 1) belongs to an important class of heterocyclic compounds due to the presence of nitrogen, oxygen and exocyclic sulphur atoms. Oxadiazole ring containing systems have remained the focus in the drug discovery programs because of their versatile nature, privileged structure (reactive pharmacophore), molecular modulating properties, ligand-binding site interactions and pharmacological profile ${ }^{[13]}$. This is especially true for the substituted 1,3,4-oxadiazoles that are reported to have a broad-spectrum pharmacological activities like antibacterial, antitubercular, antifungal, antiviral, anthelmintic, antioxidant, anticancer, central nervous system depressing, anticonvulsant, muscle relaxant, hypoglycaemic, analgesic, antiinflammatory and genotoxic ${ }^{[14-38]}$. In the recent past, OXCPM was synthesized and evaluated for drug-like characteristics using various in silico models ${ }^{[39,40]}$. Due to thiol group, the OXCPM is expected to have a significant reducing potential, which could translate into novel antioxidant effects and to prove this, the present study is attempted to explore the antioxidant potential and binding pattern of OXCPM to oxidative stress-related protein targets.

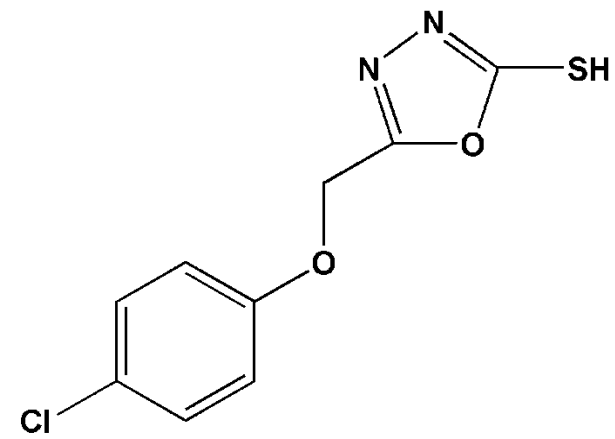

Fig. 1: Chemical structure of 5-[(4-chlorophenoxy)methyl]1,3,4-oxadiazole-2-thiol
The chemicals used and their sources are as follows. Phosphate-buffered saline tablets (PBS404.100, BioShop Canada Inc., Burlington), butylated hydroxytoluene (BHT), Tween-40, acetic acid (100\%), hydrochloric acid, trichloroacetic acid, ferric chloride, disodium hydrogen orthophosphate $\mathrm{BDH}$ Laboratory Supplies, Poole, England), $\beta$-carotene (BC), potassium ferricyanide, sodium hydroxide, ammonium heptamolybdate, potassium dihydrogen phosphate, sodium dihydrogen phosphate (Merck KGaA, Darmstdt, Germany), sodium nitroprusside dihydrate, sulfanilic acid, sulphuric acid, ammonium thiocyanate (Riedel-deHaen AG. D-3016, Seeize, Germany), ascorbic acid (AA), linoleic acid (99\%), a, adiphenyl- $\beta$-picrylhydrazyl (DPPH), chloroform, $\mathrm{H}_{2} \mathrm{O}_{2}$ (30 \% v/v) by Sigma-Aldrich Chemie, Steinheim, Germany, naphthylethylenediamine dichloride (MP Biomedicals Inc., Illkirch, France) and ferrous chloride (Uni-Chem Chemical Reagents, Karachi, Pakistan) were procured from the local chemical market. The solvents used in the study included methanol (HPLC grade, Tedia Company Inc., Fairfield, USA) and inhouse prepared double-distilled water (DDW). OXCPM was received as a gift sample from Department of Chemistry, Government College University, Lahore, Pakistan.

The equipment used were, refrigerator centrifuge (2-16KC, Sigma Laborzentrifugen, Germany), sonicator (DSA50-SK1-1.8L, Germany), thermostatic water bath (M 270, Memmert, Germany), thermostatic oven (U10, Memmert, Germany), pH meter (Hanna Instruments, Romania), rotary evaporator (HEI-VAP series, Heidolph, Germany), hot plate (S37-988, Griffin and George Ltd., Britain) and ultra-low chiller (MOF U32V) and incubator (MIR-153) by Sanyo Electric Co. Ltd., Japan, were used. The absorbance of the reaction mixtures were recorded in $1 \mathrm{~cm}$ matching quartz cell using a UV/Vis spectrophotometer $\left(\mathrm{T}^{2} 0^{+}\right.$, PG Instruments, UK).

\section{Preparation of standard and sample solutions:}

The stock solutions of AA, BHT and OXCPM of the strength $1.00 \mathrm{mg} / \mathrm{ml}$ were prepared in methanol. A range of working solutions of OXCPM $(0.10-1.00 \mathrm{mg} / \mathrm{ml})$ was prepared by diluting the stock solution with methanol.

\section{DPPH radical scavenging assay:}

This assay was performed using a method described by 
Manzocco et al. with slight modifications ${ }^{[41]}$. Briefly, an aliquot of $0.20 \mathrm{ml}$ of the sample $(0.10-1.00 \mathrm{mg} / \mathrm{ml})$ was mixed with $2 \mathrm{ml}$ of $0.50 \mathrm{mM}$ solution of DPPH radical $(\mathrm{DPPH} \cdot)$ in methanol. The mixture was incubated in the dark at room temperature for $30 \mathrm{~min}$ and the absorbance was recorded at $517 \mathrm{~nm}$ against methanol as a blank. AA and BHT were used as the standards and the test tubes containing methanol in the place of the sample served as a control. The \% radical scavenging activity was calculated using the following Eqn., \% $\mathrm{DPPH} \cdot$ scavenging activity $=\left(\left(\mathrm{A}_{\mathrm{C}}-\mathrm{A}_{\mathrm{S}}\right) / \mathrm{A}_{\mathrm{C}}\right) \times 100$, where, $A_{c}$ and $A_{s}$ denote the absorbance of control and sample, respectively.

\section{NO· scavenging assay:}

The method of Marcocci et al., with some modifications was used to evaluate the ability of the OXCPM to scavenge $\mathrm{NO}^{\cdot[42]}$. A reaction mixture containing $3 \mathrm{ml}$ sodium nitroprusside $(10 \mathrm{mM})$ in PBS ( $\mathrm{pH} 7.40)$ and $1 \mathrm{ml}$ sample $(0.10-1.00 \mathrm{mg} / \mathrm{ml})$ was incubated at $25^{\circ}$ for $150 \mathrm{~min}$ under a visible polychromatic light source (100 W tungsten lamp). Finally, $0.50 \mathrm{ml}$ of the incubated solution was mixed with equal volume of Griess reagent (mixture of equal volumes of sulfanilic acid, $0.33 \%$ in $20 \%$ glacial acetic acid and $0.10 \% \mathrm{w} / \mathrm{v}$ naphthylethylenediamine dichloride and incubated for further $30 \mathrm{~min}$. The absorbance of the resulting pinkcolored mixture was recorded at $546 \mathrm{~nm}$ against DDW as a blank. AA and BHT were used as the standards and the test tubes containing methanol in the place of OXCPM served as a control. The amount of NOscavenged was calculated using the following Eqn., \% $\mathrm{NO}$. scavenging activity $=\left[\left(\mathrm{A}_{0}-\mathrm{A}_{1}\right) / \mathrm{A}_{0}\right] \times 100$, where, $\mathrm{A}_{0}$ and $\mathrm{A}_{1}$ denote the absorbance of mixture before and after reaction with Griess reagent.

\section{$\mathrm{H}_{2} \mathrm{O}_{2}$ scavenging assay:}

The $\mathrm{H}_{2} \mathrm{O}_{2}$ scavenging assay was performed as described earlier ${ }^{[43]}$. The reaction mixture containing $1 \mathrm{ml}$ of OXCPM $(0.10-1.00 \mathrm{mg} / \mathrm{ml}), 3.40 \mathrm{ml}$ phosphate buffer $(50 \mathrm{mM}, \mathrm{pH} 7.40)$ and $0.60 \mathrm{ml} \mathrm{H}_{2} \mathrm{O}_{2}$ solution (40 mM, prepared in buffer) was incubated at room temperature. The absorbance was recorded at $240 \mathrm{~nm}$ at $0 \mathrm{~min}$ and after every $10 \mathrm{~min}$ for $40 \mathrm{~min}$. A similar reaction mixture containing the buffer in place of $\mathrm{H}_{2} \mathrm{O}_{2}$ was prepared for background subtraction. AA and $\mathrm{BHT}$ were used as the standards and the test tubes containing methanol in the place of OXCPM served as a control. The $\% \mathrm{H}_{2} \mathrm{O}_{2}$ scavenging effect was calculated using the following Eqn., $\% \mathrm{H}_{2} \mathrm{O}_{2}$ scavenging activity $=\left(\mathrm{A}_{\mathrm{C}}-\right.$ $\left.\left.\mathrm{A}_{\mathrm{S}}\right) / \mathrm{A}_{\mathrm{C}}\right) \times 100$.
The assay was performed using a method reported previously ${ }^{[44]}$. Briefly, a reaction mixture containing $2.50 \mathrm{ml}$ of phosphate buffer $(20 \mathrm{mM}, \mathrm{pH} 6.60)$, $2.50 \mathrm{ml}$ of potassium ferricyanide $(1 \% \mathrm{w} / \mathrm{v})$ and $1 \mathrm{ml}$ of sample $(0.10-1.00 \mathrm{mg} / \mathrm{ml})$ or standards (AA and BHT) or control (methanol) was incubated at $50^{\circ}$ for 20 min followed by addition of trichloroacetic acid (2.50 $\mathrm{ml}, 10 \% \mathrm{w} / \mathrm{v}$ ). The resulting mixture was centrifuged at $3000 \mathrm{rpm}$ for $10 \mathrm{~min}$ and the supernatant $(2.50 \mathrm{ml})$ was collected and mixed with equal volume of distilled water. Finally, the reaction was stopped by addition of ferric chloride $(0.50 \mathrm{ml}, 0.10 \% \mathrm{w} / \mathrm{v})$ and the resulting colored complex was analysed at $700 \mathrm{~nm}$ against DDW as the blank. Increase in absorbance of the reaction mixture was taken as a direct measure of the reducing power of the sample ${ }^{[45]}$. The percent reducing power of the OXCPM was calculated using the following Eqn., $\%$ reducing power $=\left(A_{S}-A_{C} / A_{S}\right) \times 100$.

\section{Phosphomolybdenum assay:}

Phosphomolybdenum assay was performed as described by Prieto et al. ${ }^{[46]}$. Briefly, $0.10 \mathrm{ml}$ of OXCPM $(0.10-1.00 \mathrm{mg} / \mathrm{ml})$ or standards (AA and BHT) or control (methanol) was treated with $1 \mathrm{ml}$ of the molybdate reagent $(0.60 \mathrm{M}$ sulfuric acid, $28 \mathrm{mM}$ sodium phosphate and $4 \mathrm{mM}$ ammonium molybdate in distilled water). The tubes were incubated in a thermostatic water bath at $95^{\circ}$ for $90 \mathrm{~min}$, cooled to room temperature and absorbance of the mixture was recorded at $695 \mathrm{~nm}$ against a suitable blank. Increase in the absorption of the reaction mixture indicated the antioxidant activity. The percent antioxidant activity of the OXCPM was calculated using the following Eqn., percent antioxidant activity $=\left(\mathrm{A}_{\mathrm{S}}-\mathrm{A}_{\mathrm{C}} / \mathrm{A}_{\mathrm{S}}\right) \times 100$.

\section{BC bleaching assay:}

$\mathrm{BC}$ bleaching assay was performed by the methods of Velioglu et al. ${ }^{[47]}$ and $\mathrm{Lu}$ and Foo ${ }^{[48]}$. Briefly, BC $(100.00 \mathrm{mg})$ was dissolved in $50 \mathrm{ml}$ chloroform $(2.00 \mathrm{mg} / \mathrm{ml})$ and added into a flask containing $1.00 \mathrm{~g}$ linoleic acid and $10.00 \mathrm{~g}$ Tween- 40 . The organic solvent was completely evaporated from the mixture using a rotary evaporator at $40^{\circ}$ followed by addition of $50 \mathrm{ml}$ PBS to form a stable emulsion. Aliquots $(4.70 \mathrm{ml})$ of the emulsion were added in test tubes containing $0.20 \mathrm{ml}$ of sample $(0.10-1.00 \mathrm{mg} / \mathrm{ml})$, incubated at $50^{\circ}$ in a thermostatic water bath, and the absorbance of the reaction mixture was measured immediately $(\mathrm{t}=0)$ and after every $30 \mathrm{~min}$ up to $90 \mathrm{~min}$ 
at $470 \mathrm{~nm}$. The blank consisted of an emulsion prepared in similar manner as mentioned above but devoid of BC. The percent antioxidant activity was calculated using the following Eqn., percent antioxidant activity $=1-\left[\left(\mathrm{A}_{\mathrm{T} 0}-\mathrm{A}_{\mathrm{T} 90}\right) /\left(\mathrm{A}_{\mathrm{C} 0}-\mathrm{A}_{\mathrm{C} 90}\right)+\left(\mathrm{A}_{\mathrm{S} 0}-\mathrm{A}_{\mathrm{S} 90}\right)\right] \times 100$, where, $\mathrm{A}_{\mathrm{C} 0}$ and $\mathrm{A}_{\mathrm{C} 90}, \mathrm{~A}_{\mathrm{T} 0}$ and $\mathrm{A}_{\mathrm{T} 90}$, and $\mathrm{A}_{\mathrm{S} 0}$ and $\mathrm{A}_{\mathrm{S} 90}$ are the absorbance values of the control (methanol), test sample and standards (AA and BHT), at zero time and after incubation for $90 \mathrm{~min}$, respectively.

\section{Ferric thiocyanate assay:}

The method described by Kikuzaki et al. ${ }^{[49]}$ was employed to determine the effect of OXCPM on lipid peroxidation. In the screw cap vials, a reaction mixture containing $4 \mathrm{ml}$ of the test concentration of OXCPM $(0.10-1.00 \mathrm{mg} / \mathrm{ml}), 4.10 \mathrm{ml}$ of $2.51 \%$ linoleic acid (in methanol), $8 \mathrm{ml}$ of phosphate buffer $(50 \mathrm{mM}, \mathrm{pH}$ 7.00 ) and $3.90 \mathrm{ml}$ of DDW was incubated at $40^{\circ}$ in the dark. Aliquots of $0.10 \mathrm{ml}$ of the reaction mixture were transferred to the test tubes containing $9.70 \mathrm{ml}$ methanol (100\%), $0.10 \mathrm{ml} 30 \%$ aqueous ammonium thiocyanate and $0.10 \mathrm{ml} 20 \mathrm{mM}$ ferrous chloride in $3.50 \%$ hydrochloric acid. The absorbance of the resulting mixture was measured at $500 \mathrm{~nm}$ after $3 \mathrm{~min}$ of addition of ferrous chloride. The measurements were made at $6 \mathrm{~h}$ and after every $24 \mathrm{~h}$ until the absorbance of the control reached its maximum. AA and BHT were used as positive control, and the mixture containing methanol in place of the sample served as a negative control.

\section{Statistical analyses:}

Each assay was performed in replicates and the results were presented as mean \pm standard deviation (SD). The data were analysed using one-way ANOVA and difference between groups was determined by posthoc multiple comparison, Tukey's HSD, using SPSS version 12.00. A p-value below 0.05 was considered as significant difference.

\section{Binding interactions of OXCPM with oxidative stress-related protein targets:}

The binding of the ligand (OXCPM) with two oxidative stress-related targets, protein tyrosine kinase $2-\beta$ (PTK$2 \beta$ ) and glutathione reductase (GR) was evaluated using online docking software, 1-Click Docking by Mcule, Inc., USA. The OXCPM was entered as a SMILE in the input section of the software and refined in the drawer. Afterwards, the protein target was selected from the library and docking was performed. The results were obtained as "scores" of OXCPM binding affinity with the selected targets. Moreover, the pose of the binding of the OXCPM in/on the protein surface was visualized and saved to determine the best binding conformation. The docking results were saved as "pdb" and binding site composition and average distance between the ligand and amino acid residue was determined, using two online software, 3DLigandSite by Structural Bioinformatics Group, Imperial College London and COACH by Zhang Lab, University of Michigan ${ }^{[50,51]}$.

\section{RESULTS AND DISCUSSION}

The results of antioxidant activities of OXCPM and the standards (AA and BHT), at similar concentration level $(1.00 \mathrm{mg} / \mathrm{ml})$, determined using seven in vitro methods are shown in fig. 2. The OXCPM demonstrated promising antioxidant activity in all the employed models in the order as; $\mathrm{H}_{2} \mathrm{O}_{2}$ scavenging assay $(89.30 \pm 0.013 \%)>\mathrm{DPPH} \cdot$ scavenging assay $(81.20 \pm 0.002 \%)>$ phosphomolybdenum assay $(80.52 \pm 0.016 \%)>\mathrm{NO} \cdot$ scavenging assay $(54.81 \pm 0.007$ $\%)>$ reducing power assay $(52.87 \pm 0.008 \%)>$ ferric thiocyanate assay $(34.44 \pm 0.019 \%)>\mathrm{BC}$ bleaching assay $(19.91 \pm 0.014 \%)$. It is noteworthy that antioxidant effects of OXCPM were comparable to the standards in the $\mathrm{DPPH} \cdot$ and $\mathrm{H}_{2} \mathrm{O}_{2}$ scavenging, and $\mathrm{BC}$ bleaching assays. However, in all the other models, the activity of the OXCPM was markedly lower than the standards $(p<0.05)$.

The antioxidant activity of the OXCPM in a concentration range $(0.10-1.00 \mathrm{mg} / \mathrm{ml})$ indicated a linear rise in the response on increasing the concentration. The dose-dependent antioxidant effects of the OXCPM by various in vitro methods and the respective linear

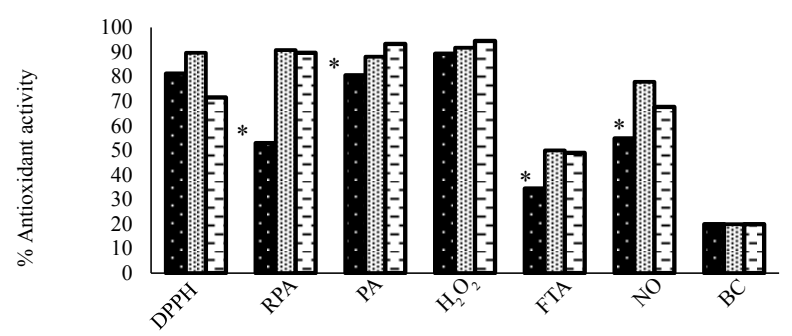

Fig. 2: Antioxidant activities of equivalent amounts of AA, BHT and $\mathrm{OXCPM}$ in in vitro assays

Comparative activities of ascorbic acid (AA), butylated hydroxytoluene (BHT) and 5-[(4-chlorophenoxy)methyl]-1,3,4oxadiazole-2-thiol (OXCPM) in seven in vitro assays. *Indicates a significant difference in the activity of OXCPM compared

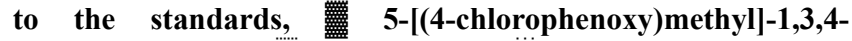
oxadiazole-2-thiol; power activity; PA: Phosphomolybdenum activity; $\mathrm{H}_{2} \mathrm{O}_{2}: \mathrm{H}_{2} \mathrm{O}_{2}$ scavenging activity; FTA: ferric thiocyanate activity; NO: NO radical scavenging activity; $\mathrm{BC}$ : $\mathrm{BC}$ bleaching activity 


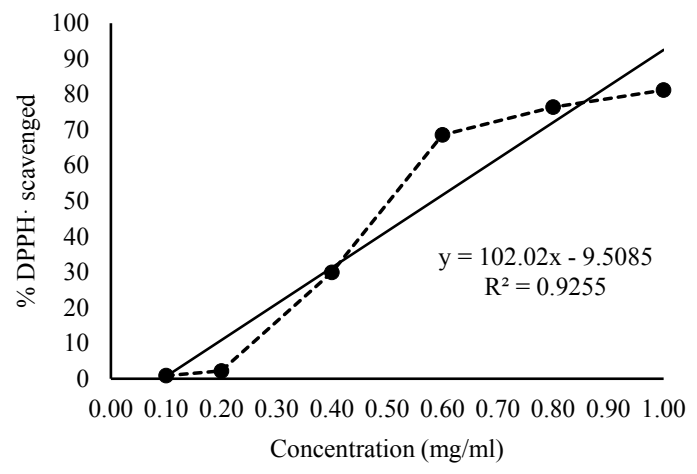

a

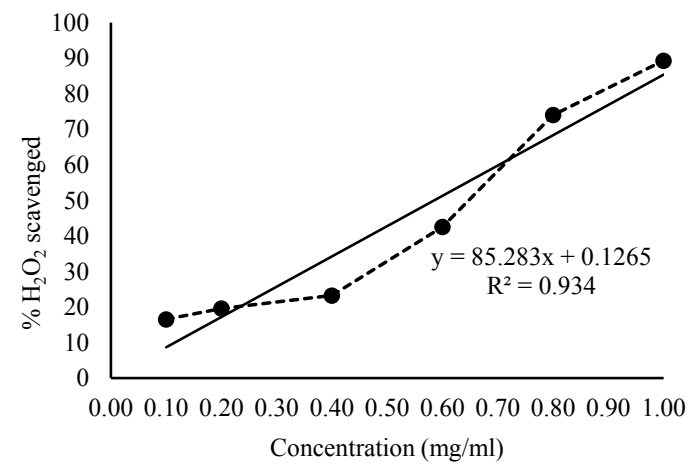

c

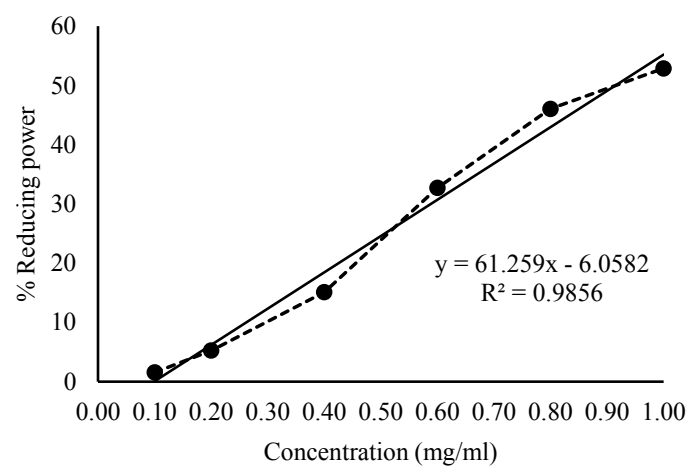

e

Fig. 3: Concentration-dependent activity of OXCPM

a. DPPH scavenging assay, b. NO scavenging assay, c. $\mathrm{H}_{2} \mathrm{O}_{2}$ scavenging assay, d. reducing power assay, e. phosphomolybdenum assay, f. $\beta$-carotene (BC) bleaching assay. All data points are mean \pm standard deviation $(\mathrm{n}=3)$. OXCPM is 5-[(4-chlorophenoxy) methyl]-1,3,4-oxadiazole-2-thiol

regression equations are shown in figs. 3a-f. The median effective concentration $\left(\mathrm{EC}_{50}\right)$ of the $\mathrm{OXCPM}$, in different in vitro antioxidant assays, calculated from the respective linear regression equations are given in Table 1.

The kinetics of OXCPM and the standards in producing the antioxidant effects was evaluated using the DPPH scavenging, $\mathrm{H}_{2} \mathrm{O}_{2}$ scavenging, $\mathrm{BC}$ bleaching and ferric thiocyanate assays. In the DPPH - scavenging assay, a sharp transition in the colour of the free radical

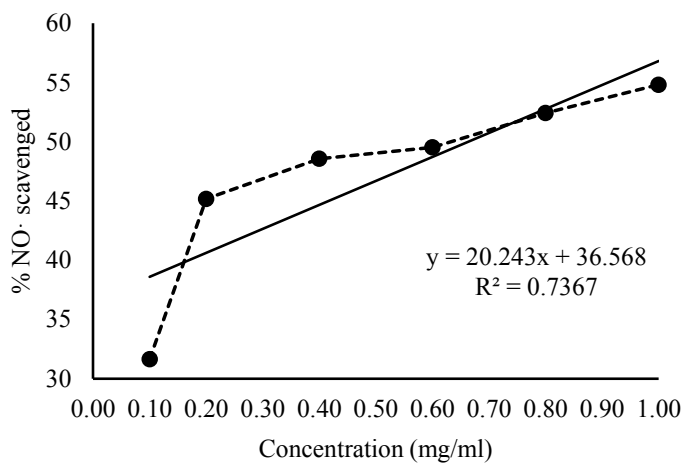

b

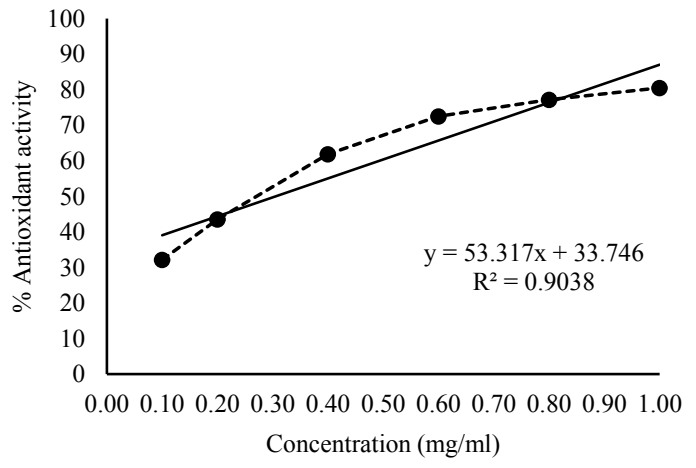

d

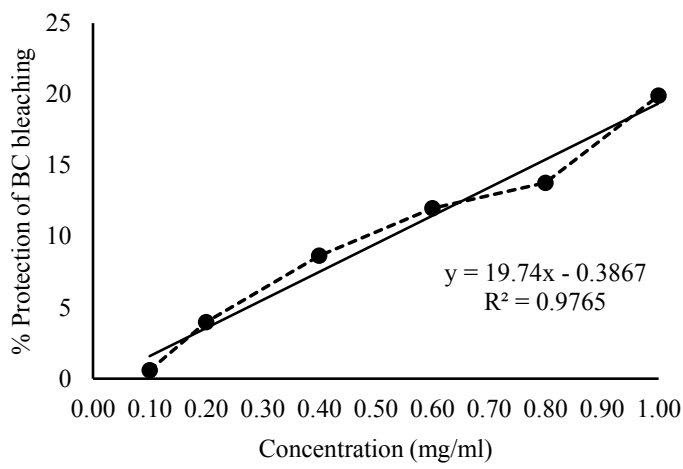

f 
TABLE 1: EC $_{50}$ VALUES OF OXCPM IN VARIOUS ANTIOXIDANT ASSAYS

\begin{tabular}{lc}
\hline Antioxidant assays & $\begin{array}{c}\text { Median effective } \\
\text { concentration }\left(\mathrm{EC}_{50,} \mathrm{mg} / \mathrm{ml}\right)\end{array}$ \\
\hline DPPH· scavenging assay & 0.58 \\
$\mathrm{NO} \cdot$ scavenging assay & 0.67 \\
$\mathrm{H}_{2} \mathrm{O}_{2}$ scavenging assay & 0.59 \\
Phosphomolybdenum assay & 0.93 \\
Reducing power assay & 0.32 \\
BC bleaching assay & 2.56
\end{tabular}

OXCPM is 5-[(4-chlorophenoxy) methyl]-1,3,4-oxadiazole-2-thiol. $\mathrm{EC}_{50}$ is median effective concentration

incubation. Similar reaction kinetics were observed in the case of AA and BHT.

The kinetics of the OXCPM and the standards in bleaching $\mathrm{BC}$ is shown in fig. 4A. A sharp decline in absorbance of the control was observed after heating for 20 min and continued until end of the study time period. However, the reaction mixtures containing OXCPM effectively inhibited the bleaching of $\mathrm{BC}$ emulsion and the absorbance of the emulsion was hence greater than the control. After 90 min incubation, the absorbance values of the emulsions containing OXCPM were not statistically different from those of BHT $(0.211 \pm 0.014$ and $0.211 \pm 0.009$, respectively $)$ and AA $(0.211 \pm 0.014$ and $0.211 \pm 0.010$, respectively). The $\%$ antioxidant activity calculated using the formula reported by Jayaprakash et al. was found to be $41.97^{[45]}$.

The kinetics of the inhibition of lipid peroxidation by OXCPM and the standards AA and BHT are shown in fig. 4B. The effects of the sample and the standards on lipid peroxidation level were investigated for six consecutive days. Throughout the study period, a gradual increase in the absorbance of the control was observed with maximum at $5^{\text {th }} \mathrm{d}$ of incubation. At $6^{\text {th }} \mathrm{d}$, a drop in the absorbance of the red-colored complex was observed in the control test tubes. The absorbance of the OXCPM at $5^{\text {th }}$ and $6^{\text {th }} \mathrm{d}$ was found markedly lower than the absorbance of control but higher than AA and BHT. The order of absorbance was found to be as control $>\mathrm{OXCPM}>\mathrm{AA}>\mathrm{BHT}$. The absorbance values for all the concentration range of the sample $(0.10-1.00 \mathrm{mg} / \mathrm{ml})$ and AA were also the highest at $5^{\text {th }} \mathrm{d}$ and decreased afterwards. The decrease in absorbance might be attributed to the formation of malondialdehyde products from oxidation of linoleic acid, however, this was not observed in the case of BHT. The percent inhibition of lipid peroxidation by OXCPM, AA and BHT at $5^{\text {th }} \mathrm{d}$ was found to be $2.93 \pm 0.034,4.64 \pm 0.014$ and $59.07 \pm 0.016 \%$, respectively. The statistical analysis indicated that the activity of OXCPM was not significantly different from that of AA. However, at similar concentrations, the activity of BHT was significantly higher than OXCPM and AA. It was noted that OXCPM and AA showed maximum response $(34.44 \pm 0.019$ and $55.50 \pm 0.026 \%$, respectively) after 24 and $6 \mathrm{~h}$ of incubation, respectively, and then a gradual decline in their activity was observed as compared to BHT, which showed maximum inhibition at $5^{\text {th }} \mathrm{d}$. The results for both the standards were found to be consistent to the previously published report ${ }^{[52]}$. Hence, it is clear from the result of the study that OXCPM has comparable lipid peroxidation protection than that of AA but the both were less active than BHT.

OXCPM interacted with the protein targets, PTK-2 $\beta$ and $\mathrm{GR}$, at the default binding sites having dimensions such as GR 1 gsn (X, 61.0056; Y, -18.9883; Z, 51.4463), GR 1xan (X, 82.1538; Y, -5.7497; Z, 36.095), GR 3grs (X, 60.8014; Y, 51.3499; Z, 18.9135), GR 3grt (X, 63.1107; Y, 37.3065; Z, 20.1816), PTK-2 $\beta$ 3et7 (X, 22.7878;
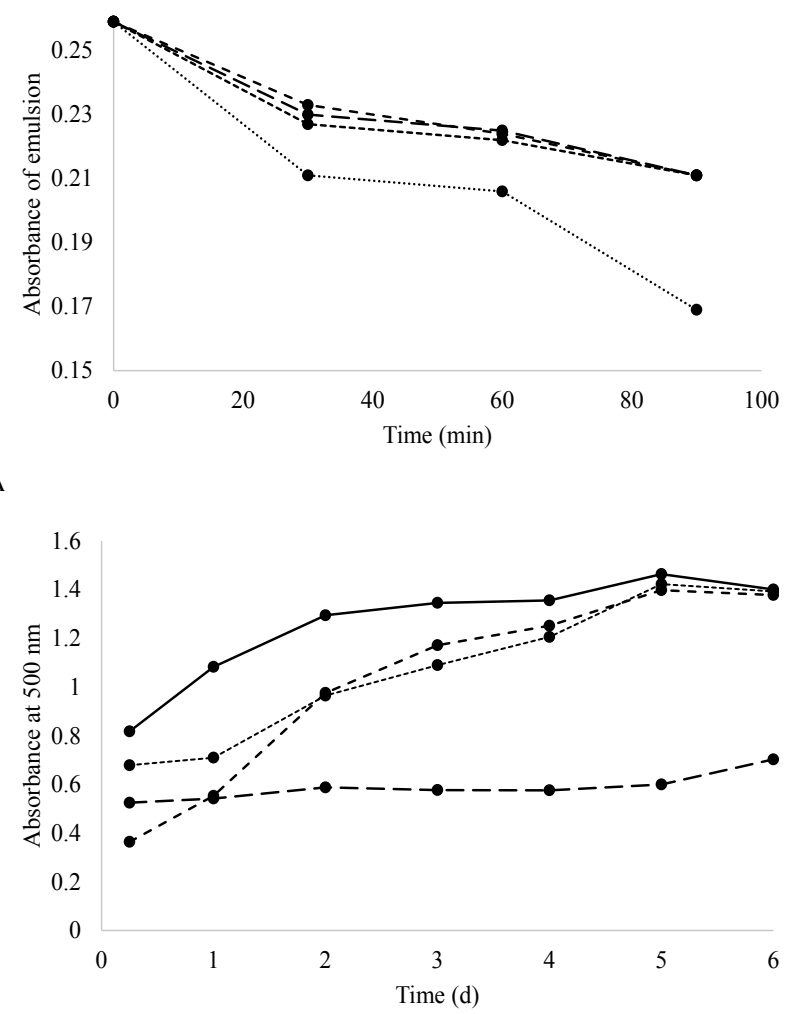

Fig. 4: Kinetics of $\mathrm{BC}$ bleaching and inhibition of lipid peroxidation by AA, BHT and OXCPM

A. $\beta$-carotene (BC) bleaching assay and $B$. inhibition of lipid peroxidation in ferric thiocyanate assay. All points represent mean \pm standard deviation of 3 determinations. A. -........ control, --๑--. 5-[(4-chlorophenoxy)methyl]-1,3,4oxadiazole-2-thiol (OXCPM, $1.00 \mathrm{mg} / \mathrm{ml}),-0-$ butylated hydroxytoluene (BHT) and - - - ascorbic acid (AA). B - - control, - - - BHT, - - -AA; $\cdots \cdot \cdots \cdot$ ОХСРМ 
Y, 65.5996; Z, 18.6962), PTK-2 $\beta$ 3fzp (X, 14.893; Y, -10.8816 ; Z, 7.0870), PTK-2 $\beta$ 3fzs (X, -3.4674; Y, -3.2746; Z, 12.4054), PTK-2 $\beta$ 3fzt (X, -4.9729; Y, -1.8823 ; Z, 11.6155), PTK-2 $\beta$ 3fzr (X, 23.0432; Y,

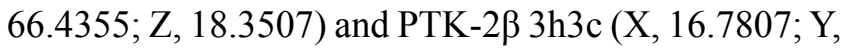
$-10.0077 ; \mathrm{Z}, 4.3928)$. The scores of OXCPM binding to these sites indicated that the OXCPM possessed good affinity towards both the targets, PTK- $2 \beta$ and GR, with maximum towards the latter (Table 2). The binding poses of OXCPM relative to the best binding score are shown in fig. 5 . These results indicate that OXCPM gives the best conformation with GR 1gsn and GR 3 grs.

The composition of binding pockets and average distance between amino acid residue and the ligand was determined for two protein targets for which OXCPM gave best scores and conformations. For GR 3grs, mammoth scores for the ligand cluster included (average InE: 51.2, min LnE: 49.6, max LnE: 51.3), and composition of the binding pocket and average distance between amino acid residue and the ligand was ILE9(0.39), GLY10(0.01), GLY11(0.05), GLY12(0.03), SER13(0.00), GLY14(0.00), GLY15 (0.01), VAL32(0.31), GLU33(0.00), SER34(0.00), HIS35(0.07), LYS36(0.34), GLY39(0.00), THR40 (0.00), CYS41(0.00), VAL44(0.30), GLY45(0.18), CYS46(0.06), LYS49(0.00), GLY111(0.06), HIS112 (0.02), ALA113(0.00), ALA138(0.12), THR139(0.01), GLY140(0.01), GLY141(0.04), SER160(0.04),TYR180 (0.00), ILE181(0.58), ARG274(0.24), LEU281(0.32), GLY313(0.09),ASP314(0.00), VAL315(0.36), LEU320 (0.03), LEU321(0.00), THR322(0.00), PRO323(0.05) and ALA325(0.57). For GR 1gsn, mammoth scores for the ligand cluster included (average InE: 50.9,

TABLE 2: BINDING SCORES OF OXCPM, AA AND BHT AGAINST PROTEIN TARGETS

\begin{tabular}{lcccc}
\hline \multirow{2}{*}{ Protein } & \multirow{2}{*}{ PDB ID } & \multicolumn{3}{c}{ Binding score } \\
\cline { 2 - 5 } & & OXCPM & AA & BHT \\
\hline \multirow{2}{*}{ Protein- } & $3 \mathrm{et} 7$ & -5.8 & -4.8 & -6.7 \\
tyrosine kinase & $3 \mathrm{fzr}$ & -6.5 & -4.9 & -6.8 \\
$2-B$ & $3 \mathrm{fzs}$ & -5.0 & -4.5 & -6.3 \\
& $3 \mathrm{fzt}$ & -6.6 & -4.6 & -7.3 \\
& $3 \mathrm{~h} 3 \mathrm{c}$ & -6.0 & -5.6 & -7.2 \\
& $1 \mathrm{gsn}$ & -6.9 & -6.2 & -6.8 \\
Glutathione & $1 \mathrm{xan}$ & -5.0 & -4.9 & -5.5 \\
reductase & $3 \mathrm{grs}$ & -7.0 & -6.3 & -5.7 \\
& $3 \mathrm{grt}$ & -5.1 & -4.7 & -5.9 \\
\hline
\end{tabular}

Binding scores against various protein targets were generated using Mcule 1-Click Docking software. OXCPM is 5-[(4-chlorophenoxy) methyl]-1,3,4-oxadiazole-2-thiol AA is ascorbic acid and BHT is butylated hydroxytoluene

November-December 2018 min LnE: 49.3, max LnE: 51.0), and composition of the binding pocket and average distance between amino acid residue and the ligand was ILE9(0.44), GLY10(0.02), GLY11(0.03), GLY12(0.02), SER13 (0.00), GLY14(0.00), GLY15(0.02), VAL32(0.39), GLU33(0.00), SER34(0.00), HIS35(0.02), LYS36 (0.32), GLY39(0.02), THR40(0.00), CYS41(0.00), VAL44(0.30), GLY45(0.33), LYS49(0.00), GLY111 (0.03), HIS112(0.00), ALA113(0.00), ALA138(0.05), THR139(0.00), GLY140(0.02), GLY141(0.02), SER160 (0.12), TYR180(0.00), ILE181(0.64), ARG274(0.10), LEU281(0.38), GLY313(0.01),ASP314(0.00), VAL315 (0.32), LEU320(0.08), LEU321(0.02), THR322(0.00), ALA325(0.56) and PHE355(0.65) $)^{[50,51]}$.

Oxidation is a chemical reaction, which involves the transfer of electrons from one molecule to the other (an oxidizing agent). The importance of oxidation reactions in the body is extensively recognized. All living organisms depend on the oxidative metabolism for their survival and this dependency results in generation of oxygen FRs and ROS. FRs, owing to their instability and high reactivity, undergo oxidative chain reactions, thus producing more radical species. In situations, when the oxidation exceeds the antioxidant defence mechanisms of the body secondary to a loss of balance between them, oxidative stress occurs ${ }^{[53]}$. The prevention against oxidative stress is possible through the use of antioxidants.

Antioxidants are the substances which slow down, prevent or terminate oxidative chain reactions being oxidized themselves, hence, are chemically reducing agents (thiols, acids or phenols) or conjugated systems. Despite controversies, use of antioxidant-based formulations has increased in the last three decades in the hope of promoting health and preventing chronic diseases ${ }^{[54]}$. However, incorporation of common synthetic antioxidants e.g. butylated hydroxyanisole, BHT, tertiary-butyl hydroquinone and propyl gallate in nutritional supplements, cosmetics and food products has been suspected to be associated with potential health hazards e.g. carcinogenesis, mutagenicity and liver injuries ${ }^{[55]}$. Hence, this situation creates a necessity for scrutinizing safe alternative synthetic antioxidants with broad-spectrum actions.

OXCPM contains a thiol group bonded to the aromatic oxadiazole ring at position 2 . The labile hydrogen group attached to sulphur makes the molecule susceptible to oxidation, thereby acting as reducing agent. Keeping in view the structural information, the present study was designed to evaluate the antioxidant potential of 

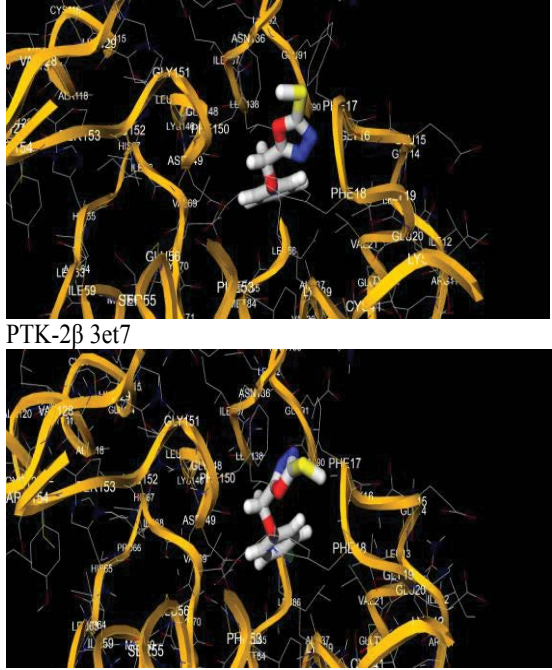

PTK-2 $\beta 3 \mathrm{fzr}$

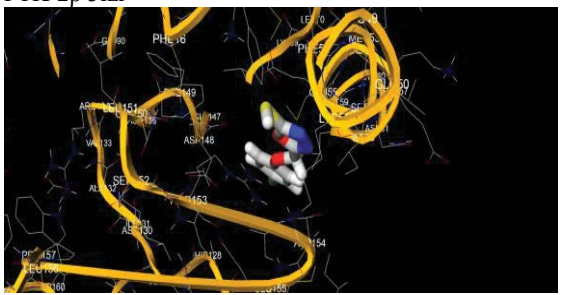

PTK-2 3 fzt
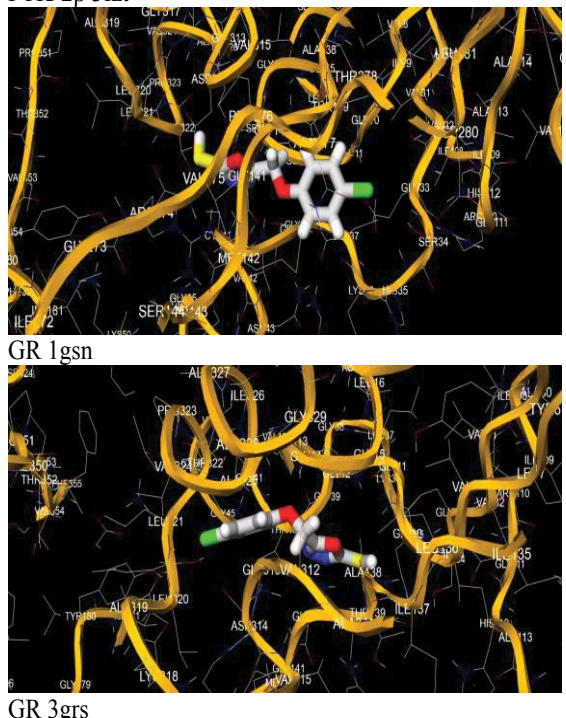

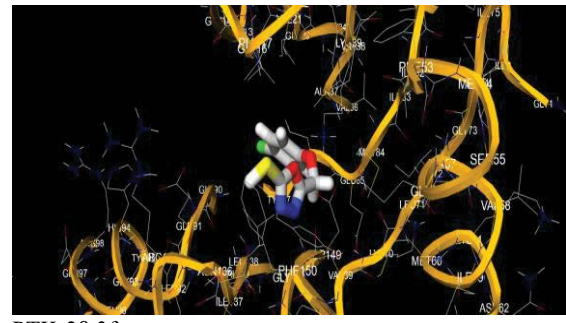

PTK-2 $\beta$ 3fzp

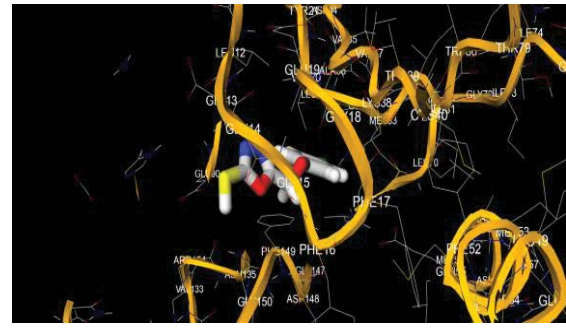

PTK-2 $\beta 3 \mathrm{fzs}$

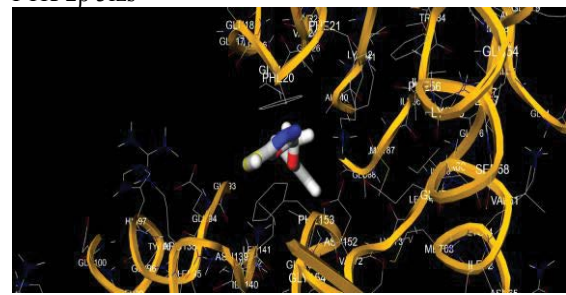

PTK- $2 \beta 3 \mathrm{~h} 3 \mathrm{c}$

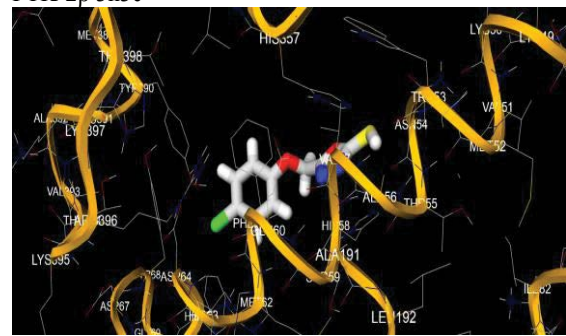

GR 1xan

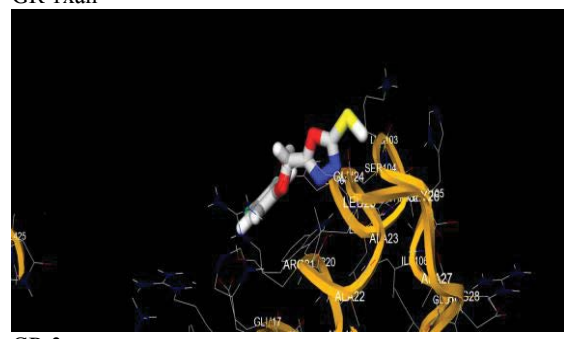

GR 3grt

Fig. 5: Best binding fits for OXPCM against oxidative stress-related endogenous targets

Protein tyrosine kinase 2-beta (PTK-2ß) and glutathione reductase (GR); carbon, hydrogen, nitrogen, oxygen, chlorine and sulphur are represented by silver, white, blue, red, green and yellow colors, respectively. 5-[(4-chlorophenoxy)methyl]-1,3,4-oxadiazole-2thiol (OXCPM)

OXCPM using seven in vitro methods detailed above. Preliminary findings of the antiradical potential of OXCPM by the DPPH assay indicated that OXCPM possessed excellent free radical scavenging potential. Later on, OXCPM was investigated for the potential to quench specific radicals involved in oxidative stress such as $\mathrm{OH} \cdot \mathrm{NO} \cdot$ and $\mathrm{LOO} \cdot$. OXCPM demonstrated good antioxidant activity against oxidative stressrelated OFR and ROS by all adopted models, however, a non-significant difference was observed between the response of OXCPM and $\mathrm{AA}$ in preventing lipid peroxidation (investigated using $\mathrm{BC}$ bleaching and ferric thiocyanate assay) and scavenging $\mathrm{H}_{2} \mathrm{O}_{2}$. The reaction kinetics by various models suggested that OXCPM was intermediate-fast antioxidant.

Though, the methods employed for evaluation of antioxidant activities gave a strong prediction of OXCPM's potential. However, the results from chemical methods cannot entirely be extrapolated to the living organisms. Several literature reports reveal 
that an antioxidant may not only exert its effect directly by quenching the FRs but also by inducing endogenous defence mechanisms ${ }^{[56,57]}$. Hence, molecular docking studies were carried out to further support the findings and evaluate molecular level interaction of OXCPM with endogenous oxidative-stress-related targets.

The ligand-protein interactions were predicted using Mcule's 1-Click Docking software, which used AutoDock Vina (with default parameters) for docking calculations, which could facilitate the drug discovery program by providing useful information regarding binding score and orientation of a particular ligand to the selected target. The software stores best-four docking poses. An important advantage of using the software was that the identity of the molecule remains un-modified during docking i.e. InChI strings of the input ligand and output conformer are compared and in case of InChI mismatch, the results are discarded.

For docking studies, PTK-2 $\beta$ was selected since it is a custodian of cell regulatory pathways and signal transduction processes and during OS, functional changes in the protein lead to destructive events ${ }^{[53]}$. GR is another endogenous defence component, which copes the OS by catalysing the reduction of glutathione disulphide to the sulfhydryl glutathione ${ }^{[58]}$. The docking results obtained indicated that BHT exhibited highest binding scores for all the subclasses of PTK- $2 \beta$ followed by OXCPM and AA. Among the subclasses of PTK$2 \beta$, BHT showed maximum affinity towards PTK-2 $\beta$ $3 \mathrm{fzs}$ and PTK-2 $\beta$ fzt, OXCPM towards PTK-2 $\beta 3 \mathrm{fzt}$ and PTK-2 $\beta$ 3fzp, and AA towards PTK-2 $\beta$ 3fzt. For glutathione reductase, maximum binding scores were obtained for OXCPM in all the subclasses except GR 1xan where BHT showed maximum affinity. OXCPM demonstrated high binding affinity for GR 3grs and $1 \mathrm{gsn}, \mathrm{BHT}$ for GR 1xan, and AsA for GR 3grs and GR $1 \mathrm{gsn}$. It is important to mention here that OXCPM and AA showed maximum binding affinities towards the same subclass of GR, but OXCPM had shown to better attach to the active site rather than AA. Hence, these results confirm the in vitro findings and indicate that the OXCPM is a putative antioxidant molecule.

The results of the present study indicated that OXCPM was a potential antioxidant that produced pleiotropic effects by scavenging a variety of OFR and ROS. Moreover, its strong binding affinities for PTK-2 $\beta$ and GR revealed that it possessed the ability to induce the endogenous defence system. Hence, it has the potential to be developed into an effective antioxidant drug.
Nonetheless, more data revealing its safety and in vivo antioxidant potential is needed.

\section{Acknowledgements:}

One of the authors, NS thanks the authorities of the University of the Punjab, Lahore, Pakistan, for providing chemicals/solvents and laboratory facilities to conduct the study. Authors thank Dr S. Z. Siddiqui, Department of Chemistry, Government College University, Lahore, Pakistan for providing a gift sample of OXCPM.

\section{Conflict of interest:}

There is no conflict of interest, financial or otherwise associated with this project.

\section{Financial support and sponsorship:}

Nil.

\section{REFERENCES}

1. McCord JM. The evolution of free radicals and oxidative stress. Am J Med 2000;108:652-9.

2. Zheng M, Storz G. Redox sensing by prokaryotic transcription factors. Biochem Pharmacol 2000;59:1-6.

3. Gilgun-Sherki Y, Melamed E, Offen D. Oxidative stress induced-neurodegenerative diseases: the need for antioxidants that penetrate the blood brain barrier. Neuropharmacology 2001;40:959-75.

4. Zandi PP, Anthony JC, Khachaturian AS, Stone SV, Gustafson $\mathrm{D}$, Tschanz JT, et al. Reduced risk of Alzheimer disease in users of antioxidant vitamin supplements-The Cache County Study. Arch Neurol 2004;61:82-8.

5. Fang YZ, Yang S, Wu G. Free radicals, antioxidants, and nutrition. Nutrition 2002;18:872-9.

6. Smith MA, Rottkamp CA, Nunomura A, Raina AK, Perry G. Oxidative stress in Alzheimer's disease. Biochim Biophys Acta 2000;1502:139-44.

7. Arteel GE. Oxidants and antioxidants in alcohol-induced liver disease. Gastroenterology 2003;124:778-90.

8. Kinnula VL, Crapo JD. Superoxide dismutases in malignant cells and human tumors. Free Radical Bio Med 2004;36:718-44.

9. Hyun DH, Hernandez JO, Mattson MP, de Cabo R. The plasma membrane redox system in aging. Aeging Res Rev 2006;5:209-20.

10. Guidi I, Galimberti D, Lonati S, Novembrino C, Bamonti F, Tiriticco M, et al. Oxidative imbalance in patients with mild cognitive impairment and Alzheimer's disease. Neurobiol Aging 2006;27:262-9.

11. Singh U, Jialal I. Oxidative stress and atherosclerosis. Pathophysiology 2006;13:129-42.

12. Sas K, Robotka H, Toldi J, Vecsei L. Mitochondrial, metabolic disturbances, oxidative stress and kynurenine system, with focus on neurodegenerative disorders. J Neurol Sci 2007;257:221-39.

13. de Oliveira CS, Lira BF, Barbosa-Filho JM, Lorenzo JG, de 
Athayde-Filho PF. Synthetic approaches and pharmacological activity of 1, 3, 4-oxadiazoles: A review of the literature from 2000-2012. Molecules 2012;17:10192-231.

14. Maillard J, Vincent M, Morin R, Bernard M. Hypnotic and sedative drug, 2-(o-hydroxyphenyl)-1, 3, 4-oxadiazole: French Pat M379. Chem Abstr 1962;57:15251g.

15. Yale HL, Losee K. 2-Amino-5-substituted 1, 3, 4-oxadiazoles and 5-imino-2-substituted $\Delta 2-1,3,4$-oxadiazolines. A group of novel muscle relaxants. J Med Chem 1966;9:478-83.

16. Husain MI, Kumar A, Srivastava RC. Synthesis of N-(2Naphthyloxyacetyl) thiosemicarbazides and 2-arylamino-5(2-naphthyloxymethyl)-1, 3, 4-thiadiazoles/oxadiazoles as oral hypoglycemic agents. Curr Sci 1986:644-6.

17. Boschelli DH, Connor DT, Bornemeier DA, Dyer RD, Kennedy JA, Kuipers PJ, et al. 1, 3, 4-Oxadiazole, 1, 3, 4-thiadiazole, and 1, 2, 4-triazole analogs of the fenamates: In vitro inhibition of cyclooxygenase and 5-lipoxygenase activities. J Med Chem 1993;36:1802-10.

18. Girges MM. Synthesis and pharmacological evaluation of novel series of sulfonate ester-containing 1, 3, 4-oxadiazole derivatives with anticipated hypoglycemic activity. Arzneimittelforschung 1994;44:490-5.

19. Yang GF, Liu ZM, Qing XH. Synthesis of 5, 7-dimethyl-2(5-substituted-1, 3, 4-oxadiazole-2-yl)-methylenethio-1, 2, 4-triazolo $[1,5-\mathrm{a}]$ pyrimidines as potential fungicides. Chin Chem Lett 2001;12:877-80.

20. Khan MSY, Khan RM, Drabu S. Anticonvulsant and antibacterial activity of some new 1, 3, 4-oxadiazole derivatives. Indian J Heterocycl Chem 2001;11:119-22.

21. Maslat AO, Abussaud M, Tashtoush H, Al-Talib M. Synthesis, antibacterial, antifungal and genotoxic activity of bis-1, 3, 4-oxadiazole derivatives. Pol J Pharmacol 2002;54:55-60.

22. Zou XJ, Lai LH, Jin GY, Zhang ZX. Synthesis, fungicidal activity, and 3D-QSAR of pyridazinone-substituted 1, 3, 4-oxadiazoles and 1, 3, 4-thiadiazoles. J Agric Food Chem 2002;50:3757-60.

23. Küçükgüzel ŞG, Oruç EE, Rollas S, Şahin F, Özbek A. Synthesis, characterisation and biological activity of novel 4-thiazolidinones, 1, 3, 4-oxadiazoles and some related compounds. Eur J Med Chem 2002;37:197-206.

24. Almasirad A, Tabatabai SA, Faizi M, Kebriaeezadeh A, Mehrabi N, Dalvandi A, et al. Synthesis and anticonvulsant activity of new 2-substituted-5-[2-(2-fluorophenoxy) phenyl]-1, 3, 4-oxadiazoles and 1, 2, 4-triazoles. Bioorg Med Chem Lett 2004;14:6057-9.

25. Zarghi A, Faizi M, Shafaghi B, Ahadian A, Khojastehpoor HR, Zanganeh $\mathrm{V}$, et al. Design and synthesis of new 2-substituted5-(2-benzylthiophenyl)-1, 3, 4-oxadiazoles as benzodiazepine receptor agonists. Bioorg Med Chem Lett 2005;15:3126-9.

26. Holla BS, Poojary KN, Bhat KS, Ashok M, Poojary B. Synthesis and anticancer activity studies on some 2-chloro-1, 4-bis-(5-substituted-1, 3, 4-oxadiazol-2-ylmethyleneoxy) phenylene derivatives. Indian J Chem 2005;44:1669-73.

27. Ouyang X, Piatnitski EL, Pattaropong V, Chen X, He HY, Kiselyov AS, et al. Oxadiazole derivatives as a novel class of antimitotic agents: Synthesis, inhibition of tubulin polymerization, and activity in tumor cell lines. Bioorg Med Chem Lett 2006;16:1191-6.

28. Almasirad A, Vousooghi N, Tabatabai SA, Kebriaeezadeh A, Shafiee A. Synthesis, anticonvulsant and muscle relaxant activities of substituted 1, 3, 4-oxadiazole, 1, 3, 4-thiadiazole and 1, 2, 4-triazole. Acta Chim Slov 2007;54:317-24.

29. Akhtar T, Hameed S, Al-Masoudi NA, Loddo R, La Colla P. In vitro antitumor and antiviral activities of new benzothiazole and 1, 3, 4-oxadiazole-2-thione derivatives. Acta Pharm 2008;58:135-49.

30. Akhter M, Husain A, Azad B, Ajmal M. Aroylpropionic acid based 2, 5-disubstituted-1, 3, 4-oxadiazoles: synthesis and their anti-inflammatory and analgesic activities. Eur J Med Chem 2009;44:2372-8.

31. El-Sayed WA, El-Essawy FA, Ali OM, Nasr BS, Abdalla MM, Abdel-Rahman AAH. Anti-HIV activity of new substituted 1, 3, 4-oxadiazole derivatives and their acyclic nucleoside analogues. Z Naturforsch C 2009;64:773-8.

32. Dewangan D, Pandey A, Sivakumar T, Rajavel R, Dubey RD. Synthesis of some novel 2, 5-disubstituted 1, 3, 4-oxadiazole and its analgesic, anti-inflammatory, anti-bacterial and antitubercular activity. Int J ChemTech Res 2010;2:1397-412.

33. Patel K, Jayachandran E, Shah R, Javali V, Sreenivasa GM. Synthesis, characterization and anthelmintic activity (Perituma posthuma) of new oxadiazole incorporated with imidazole and pyrazole. Int J Pharma Bio Sci 2010;1:1-14.

34. Almasirad A, Shafiee A, Abdollahi M, Noeparast A, Shahrokhinejad N, Vousooghi N, et al. Synthesis and analgesic activity of new 1, 3, 4-oxadiazoles and 1, 2, 4-triazoles. Med Chem Res 2011;20:435-42.

35. Salimon J, Salih N, Hussien H. Synthesis and antimicrobial activity of 1-(5-mercapto-1, 3, 4-oxadiazol-2-yl)-2-(pyridine2-ylamino) ethanone. Sains Malays 2011;40:445-50.

36. Kotaiah Y, Harikrishna N, Nagaraju K, Venkata Rao C. Synthesis and antioxidant activity of 1, 3, 4-oxadiazole tagged thieno [2, 3-d] pyrimidine derivatives. Eur J Med Chem 2012;58:340-5.

37. Almasirad A, Mousavi Z, Tajik M, Assarzadeh MJ, Shafiee A. Synthesis, analgesic and anti-inflammatory activities of new methyl-imidazolyl-1, 3, 4-oxadiazoles and 1, 2, 4-triazoles. Daru 2014;22:22-9.

38. Alp AS, Kilcigil G, Özdamar ED, Çoban T, Eke B. Synthesis and evaluation of antioxidant activities of novel 1, 3, 4-oxadiazole and imine containing $1 \mathrm{H}$-benzimidazoles. Turk J Chem 2015;39:42-53.

39. Siddiqui SZ, Abbasi MA, Rehman A, Irshad M, Ashraf M, Ahmad I, et al. Synthesis, pharmacological evaluation, molecular docking and cytotoxicity studies on some n-substituted 5-[(4-chlorophenoxy) methyl]-1, 3, 4-oxadiazole-2yl-2-sulfanyl acetamides. Indo Am J Pharm Res 2014;4:3603-17.

40. Shehzadi N, Hussain K, Islam M, Bukhari NI, Khan MT, Salman $\mathrm{M}$, et al. In silico drug-qualifying parameters of 5-[(4-chlorophenoxy) methyl]-1, 3, 4-oxadiazole-2-thiol. Lat Am J Pharm 2016;35:1991-7.

41. Manzocco L, Anese M, Nicoli MC. Antioxidant properties of tea extracts as affected by processing. Lebensm Wiss Technol 1998;31:694-8.

42. Marcocci L, Maguire JJ, Droy-Lefaix MT, Packer L. The nitric oxide scavenging properties of Ginkgo biloba extract EGb 761. Biochem Biophys Res Commun 1994;201:748-75.

43. Ruch RJ, Cheng SJ, Klaunig JE. Prevention of cytotoxicity and inhibition of intercellular communication by antioxidant catechins isolated from Chinese green tea. Carcinogenesis 1989;10:1003-8.

44. Oyaizu M. Studies on products of browning reactions: 
antioxidant activities of products of browning reaction prepared from glucosamine. J Nutr 1986;44:307-15.

45. Jayaprakash GK, Singh RP, Sakariah KK. Antioxidant activity of grape seed extracts on peroxidation models in vitro. J Agr Food Chem 2001;55:1018-22.

46. Prieto P, Pineda M, Aguilar M. Spectrophotometric quantitation of antioxidant capacity through the formation of a phosphomolybdenum complex: specific application to the determination of vitamin E. Anal Biochem 1999;269:337-41.

47. Velioglu YS, Mazza G, Gao L, Oomah BD. Antioxidant activity and total phenolics in selected fruits, vegetables, and grain products. J Agric Food Chem 1998;46:4113-7.

48. Lu Y, Foo LY. Antioxidant and radical scavenging activities of polyphenols from apple pomace. Food Chem 2000;68:81-5.

49. Kikuzaki H, Usuguchi J, Nakatani N. Constituents of Zingiberaceae I. Diarylheptanoid from the rhizomes of ginger (Zingiber officinale Roscoe). Chem Pharm Bull 1991;39:120-2.

50. Wass MN, Kelley LA, Sternberg MJ. 3DLigandSite: predicting ligand-binding sites using similar structures. Nucleic Acids Res 2010;38:W469-73.

51. Yang J, Roy A, Zhang Y. Protein-ligand binding site recognition using complementary binding-specific substructure comparison and sequence profile alignment. Bioinformatics
2013;29:2588-95.

52. Rezaeizadeh A, Zuki ABZ, Abdollahi M, Goh YM, Noordin MM, Hamid M, et al. Determination of antioxidant activity in methanolic and chloroformic extracts of Momordica charantia. Afr J Biotechnol 2011;10:4932-40.

53. Yoshikawa T, Naito Y. What is oxidative stress? Japan Med Assoc J 2002;45:271-6.

54. Devasagayam TP, Tilak JC, Boloor KK, Sane KS, Ghaskadbi SS, Lele RD. Free radicals and antioxidants in human health: current status and future prospects. J Assoc Physicians India 2004;52:794-804.

55. Gülçin I, Büyükokurog`lu ME, Oktay M, Küfreviog`lu ÖI. On the in vitro antioxidative properties of melatonin. J Pineal Res 2002;33:167-71.

56. Bizunok NA. Structural determinants of antioxidative activity of the phenols, diphenols and polyphenols at reactive oxygen species generated by macrophages in a different microenvironment circumstances. OJCD 2013;1:84-94.

57. Ching-Hsein C, Miao-Ling L, Ping-Lin O, Jen-Tsung Y. Novel multiple apoptotic mechanism of shikonin in human glioma cells. Ann Surg Oncol 2012;19:3097-106.

58. Deponte M. Glutathione catalysis and the reaction mechanisms of glutathione-dependent enzymes. Biochim Biophys Acta 2013;1830:3217-66. 